\title{
Language-Culture Pyramid in the Era of Belt and Road
}

\author{
Aidong Zhang and Yongqing Fang
}

\begin{abstract}
Belt and Road", or "One Belt, One Road" (OBOR) was initiated by P.R. China in 2013 and has since been embraced extensively worldwide. It involves more than $\mathbf{7 0}$ countries with total population over 4.5 billion and over 50 official languages of 9 major language families, as well as numerous dialects. How to build a solid language and cultural infrastructure to facilitate such complex across-country cooperation on the platform? This paper proposes the model of Language and Culture Pyramid, constructed in three layers of intelligence: Language Intelligence, Culture Intelligence, and Philosophy Intelligence. Strategies to develop language and culture capacity and groom respective talents are discussed at the end.
\end{abstract}

Index Terms-Belt and Road (One Belt, One Road), language culture pyramid, Language Intelligence (LQ), Philosophical Intelligence (PQ), Culture Intelligence (CQ).

\section{INTRODUCTION}

"Belt and Road" or "One Belt, One Road (OBOR)" or is the abbreviation of the "Silk Road Economic Belt" and the "21st-century Maritime Silk Road." This cooperative development initiative is a strategic vision proposed by President $\mathrm{Xi}$ Jinping. It relies on existing bilateral and multilateral collaboration between China and other involved countries, using regional cooperation platform to establish and inter-connect various economic zones. It stretches across Eurasian continent, links up with Asian Pacific economic rim on the east, and European economic rim on the west. The OBOR will ultimately form an economic integration in the continents of Asia, Europe, and Africa. In the next ten years, the over 70 OBOR countries with about 4.5 billion population will have a collective GDP accounting about $60 \%$ of the world total GDP, and trades amount of 20 trillion [1].

Historically, the "overland silk road" was a major thoroughfare for China to engage in economic and cultural exchanges with Central Asia, West Asia and Europe. OBOR inherits and enhances the ancient concept of "Silk Road" to develop economic cooperation with several dozen countries along the way. It aims to integrate economic development, improve livelihood of these countries, and create a multidimensional community with mutual political trust, economic integration and culture inclusiveness. With China as the centre of interconnection for the future world economy, OBOR will fully utilize China's competitive advantage in infrastructure investment and construction. When China's massive production capacity meets extensive needs in OBOR countries, a new "co-production capacity" will be able to create even greater value. This will mark a major historic

Manuscript received July 10, 2019; revised October 10, 2019.

The authors are with Asian Language and Culture, NIE, Nanyang Technological University, Singapore (e-mail: wenxionguri@gmail.com). turning since the industrial revolution in the UK 200 years ago, and Great Britain connected the world through its maritime power network. Thus, the world shall witness a new axis for the future global order.

\section{The Past And PResence of One Belt, One RoAD}

The Silk Road in history was the trade route leading to the west of Eurasian continent. During the Western Han Dynasty (206 BC - 9 AD), while Emperor Han Wudi (156-87 BC) was on the throne, imperial envoy Zhang Qian led explorers from Chang'an to the Western Regions. There he joined forces with the Yueshi people (an ancient Indo-European people) and fought against the Xiongnu, paving the way for the trade corridor for the first time. Subsequently, the Han court frequently sent envoys to the west, and the farthest they reached was Lixuan (today's Egyptian port of Alexandria). The Silk Road was once cut off towards the end of Western Han period, but 58 years later, the route to the Western Regions reopened during the Eastern Han (25 AD - 220 AD) period, and for the first time, the Eastern Han capital of Luoyang and the Roman Empire were connected. With Chinese silk being the most representative of the goods on this trading route of about 7000 kilometres, it was named the "Silk Road [2]" by a German expeditioner, Richthofen, in 1877 [3]. Silk Road played a huge role in promoting the ancient trade and cultural exchanges between Asia and Europe.

The nations in central Asia within the Silk Road economic belt are all developing countries. Their overall productivity is low, while its infrastructure hasn't been well developed. However, they have abundant minerals and natural resources. In the past 20 years, China has established a complementary trade relationship with these countries. The building of Silk Road economic belt with railroads linking Europe and Asia can bring considerable benefits for them right from the start by further integrating their economies with Chinese economy. As this economic belt extends and grows, the development of these destination nations will continue to reap more benefits.

The Maritime Silk Road originated during the Han Dynasty. By then the sea route between Nanyue Kingdom and the Indian Peninsular had already opened. After Emperor Han Wudi conquered Nanyue, the Han court was able to expand the scale of its maritime trade [4]. The South China Sea route that began from China and navigated westward. After the Song Dynasty (960-1279), as the south of China further developed and with Chinese economic gravity expanded southward, the maritime routes that originated from Guangzhou, Quanzhou and Hangzhou continued to advance. It went from Southeast Asia to the Arabian Sea, even going as far as the east coast of Africa. These various maritime trade routes eventually formed the "Maritime Silk 


\section{Road [4]."}

The ancient overland and maritime Silk Roads played important roles in promoting trades and cultural exchanges in history. However, the developments of global trade and maritime transportation after the Industrial Revolution in the UK led to the establishment of a new trading network dominated by sea routes. The world then entered the era of sea power.

\section{CHINA ON THE RISE}

The world has been witnessing the revival of an ancient civilization in $21^{\text {st }}$ century. The development journey for People's Republic of China has experienced three thirty-year consequential episodes, characterized as "standing up", "getting rich", and "becoming strong" [5] by their distinctive characteristics respectively. The first episode was from 1949 through 1979. It constructed a relatively comprehensive industrial systems and infrastructure. The second (1979-2009) was the reform period, while the Chinese economy developed rapidly and positioned as the second largest economy in the world. China is now in its third episode in which its economic growth has expanded beyond its boarder and integrated with many countries in the world. It has also become one of the most important political entity within the international community.

The bilateral and multi-lateral cooperation has benefited many along the OBOR. With a highly developed production system covering various industries, China found new focus and new market for its products and, as same time, new supplies of resource and energy. In return, its partners obtained capital and technology for their own respective development.

OBOR now covers Europe, Central Asia, Southeast Asia, and Africa. In Africa, for example, it integrates with African Union's 50-year grand blueprint. China-Arica cooperation covers 10 major areas: industrial cooperation program, modernization of agriculture cooperation program, infrastructure cooperation program, financial cooperation plan, the green development cooperation, trade and investment facilitation and cooperation plan, poverty reduction cooperation program, public health cooperation program, cultural cooperation program, peace and security cooperation program. [6] China proposed a plan of providing 60 billion USD in three years [6].

\section{LANGUAGE - CULTURE INFRASTRUCTURE FOR OBOR}

\section{A. The OBOR Development Strategy Requires the Support of Human Capital}

OBOR initiative entails multiple industries. It spreads over (1) High-speed rail, oil and gas pipelines, ports, and other infrastructure, (2) Pertinent facilities, equipment, follow-up services, and technical support, (3) mega-projects such as mining, oil and gas fields, (4) Financial services, such as the Silk Road Fund, BRICS Development Bank, the Asian Infrastructure Investment Bank (AIIB), etc. If the earlier mentioned China-Arica cooperation is used as a template, OBOR, then, across multiple fields of industry, agriculture, commerce, education, health, military and other disciplines. The people from various countries with diverse background of culture, language, skills, etc, will join the collective effort.

In general, the selection and appointment of workforce begin with the commencement of the project, and the staffing needs have to be constantly adjusted and enhanced as a project progresses. Throughout the entire process, the professional capacities required, including engineering and management capabilities are the priorities for consideration. However, the personnel who participate in transnational projects must have appropriate language and culture capabilities suitable for their responsibilities and environments.

\section{B. The Language Requirement of Human Resources}

There are over 70 nations involved along the way of OBOR, including 5 countries in central Asia, 11 in Southeast Asia, 2 in Northeast Asia, 5 CIS countries, 8 in South Asia, 16 in West Asia and North Africa, 16 countries [7] in central and eastern Europe. The Eurasian railway passes the western Europe and reaches UK, linking these countries to OBOR. Within these countries, there are over 60 official languages in nine linguistic families and countless dialects and minority languages. In India alone, there are 1652 minority languages and dialects [8]. When OBOR connects to Africa, the number of languages and dialects will be even more staggering.

Whenever a project cuts across ethnic and national lines, communication often becomes a significant challenge. In most cases, the foreign language capability of professionals such as engineers and construction operators is limited, while the professional translators on the other hand lack technical expertise. As a result, when contemporary linguistic experts discuss about "language as a right" and "language as a resource [9]," the traditional concept of "language as a problem" still exists, and it is still a big one!

\section{1) Challenges from language}

Training of language experts for less-spoken and difficult languages deserves more attention. Even for the popular languages, such as English, trade knowledge is frequently needed to facilitate communications in daily work in the field. As such, challenges are in two fronts: language capacity and professional knowledge. Very often, technical workers feel foreign language challenging, while the linguistic workers found the second one is at their disadvantage.

\section{2) Challenges from Culture}

Regardless of the popularity of languages, the cultural understanding of these countries must also be enhanced. Even among English speakers, there are different ethnic and cultural backgrounds. For example, among English speakers in Singapore, there are strait-born Chinese or Peranakans, as well as the new generation of "Singlish" speakers. All are distinctive from other English speakers, e.g., from UK or America. As such, cross cultural training is necessary to enhance their cultural intelligence (CQ) [10].

The absence of cross-cultural training has long been identified as one of the major reasons causing high failure rate in international business [11].The recent cases of low sensitivity to international politics, trapped international brands, such as Marriott, Delta, Zara, Medtronic, etc, into public relation worry. Actions had to be taken at company level and at operational level to rectify the situation [12]. It 
clearly demonstrated that cross-culture training need to be part of the capacity portfolio building. Such training should be offered to all people involved in OBOR projects in particular, and international business and exchange in general.

The competency profiling [13] of human resources in management study identifies language and culture intelligence constitute a part of comprehensive fundamental capability. It is an important pre-requisite for cross cultural and transnational work in today's world.

\section{The Model of Language-Culture Pyramid}

The language and culture talents discussed in this paper, is beyond the general sense of linguistic ability at micro level. As the configuration of linguistic and cultural capability would be in the shape of a pyramid. Fang and Zhang have proposed a model called "Language-Culture Pyramid", or LCP [14], [15].

\section{A. The Primary-Layer of the Pyramid -- Language Intelligence ( $L Q)$}

Linguistic Intelligence as a part of Howard Gardner's multiple intelligence theory [16], refers to individuals' ability to understand, speak, and write a language [17]. However, the language intelligence layer of LCP model connotates more than linguistics. On top of spoken and written skills, language intelligence also includes nonverbal language, as well as semiotics, etiquette, etc. It is the ability to communicate effectively, such as coding and decoding the content of messages, achieving the level of faithfulness, accuracy and elegance required, a set of century-long Chines criteria for translation, xin (信), $d a$ (达), ya (雅). Translators who are proficient in both languages can help remove communication barriers. In addition, they also need to have knowledge of cultures and customs on both sides, as well as the proper usage in communication. Appropriate dress, etiquette, body-language, and manner, could help to create smooth and harmonious atmosphere of exchange.

\section{B. The Second Layer of the Pyramid -- Cultural Intelligence $(C Q)$}

Cultural intelligence refers to "the ability of a person to operate effectively in different countries, cultures and organizations" [18] It calls for adaptability and resilience, with which one is capable of understanding and adapting to different cultures in various unfamiliar societal environments. The concept of CQ is applicable to various fields of business, education, government, and academic research [19]. CQ can also be measured. It can be obtained and enhanced through education and experiential learning [20].

\section{The Third Layer of the Pyramid -- Philosophical Intelligence $(P Q)$}

It extended from the understanding of language and culture, to include various disciplines of history, geography, philosophy, religions, politics, and economics, among others. A true mastery of the wisdom enables one to possess the insights of the world, to identify trends and provide reference and planning for macro and strategic vision, objectives, and blueprint. OBOR is such an example which is enlightened from history and will make a major impact in contemporary world. For example, Professor Zhang Weiwei of Fudan University, Shanghai, started out as an interpreter for high-level government officials, including the late Mr Deng Xiaoping. The extensive exposure to international affairs, as well as cultures, histories, etc, enriched his mind. He eventually became a well-known scholar of international affairs and international politics. Another example is Prof Kishore Mahbubani, Dean of Lee Kuan Yew School of Public Administration in Singapore. His career as a veteran diplomat developed him a global perspective. His views on the international affairs and the future oriented perspectives are very much valued and respected.

The three layers discussed above form a pyramid of language and cultural capabilities. The top layer, Philosophical Intelligence, enable and facilitate macro-level decisions, while the bottom of the pyramid contributes to operation and implementation, ensuring that the right things are "done right."

\section{BUILDING UP THE LANGUAGE-CULTURE PYRAMID}

The building of Language and Culture Pyramid requires the concerted efforts of many parties.

\section{A. Language Capacities}

To carry out OBOR planning, the cooperation and liaison in the projects, staff in both headquarters and field need to communicate constantly. The foreign language capabilities of business managers and operational staff is usually at their disadvantage. Therefore, language ability shall be an indispensable part of the training. There will be a huge demand for language teachers.

However, many countries involved in the OBOR, such as the five central Asian countries, their languages belong to small language families. Very limited teaching and training resources are available outside of the region. Their domestic supply for the language teachers is inadequate to provide language training on such a large scale.

It would be more efficient if the governments take a lead to tackle this issue. In 2016, the Ministry of Education of China, set up a five-polar policy structure of cooperation with participating countries: educational policies, collaboration channels, languages, cultural exchange, and mutual authentication of degrees. To implement, it rolled out four programs: student exchanges, cooperative curriculum, teacher training, and human resource development. [21] In 2016, China sent out 3291 language teachers to OBOR countries, $24 \%$ over the previous year. By 2017, China has signed agreement for mutual authentication of degrees with 24 OBOR countries, about half of such agreements China has ever signed [22].

China's National Committee for Education and Committee for Language would be more resourceful to coordinate with relevant language universities to deploy appropriate faculties, to ensure the adequate supply of various linguistic talents in the right places and right time. Currently, the universities in Xin Jiang Autonomic Region of West China offers languages used in Central Asia, and universities in Guangxi and Yunnan provinces of southern China offer Southeast Asia languages. Both are aligned with cross-boarder governmental 
cooperation between China and neighbouring countries.

Chinese language has also been designated as a part of curriculum in many countries along OBOR. In Russia, for example, studying Mandarin is becoming increasingly popular among Russian students. According to the government data, at least 5,000 students in Russia currently take Mandarin as part of their high school programme. This has prompted authorities to add it as an optional foreign language in Russia's college entrance exam along with English, French, Spanish and German. The experiment launched in Moscow, St Petersburg, and the country's Far East. [23] Russian education authorities announced on March 14, 2018, that Mandarin Chinese will be designated as an elective subject in high school graduation exam [24].

Beijing University in China launched a public course project for OBOR foreign language and cultural series [25] since 2015. Students in the University can choose from 40 different linguistic courses, such as Arabic, Hebrew, and Russian, and 8 OBOR cultural courses, which basically covered all major languages used in countries along OBOR. While nurturing students' linguistic skills, this project also focuses on cultural observations of countries along OBOR. They plan to offer relevant courses on culture and society such as the contemporary Arab World, the culture of Southeast Asia, and the history of Chinese-Russian exchanges. In addition, the school will regularly organize language related cultural day activities, such as West Africa Cultural Day, East Africa Cultural Day, at the same time inviting foreign ambassadors and diplomats stationed in China to talk about their impressions of OBOR.

\section{B. Cultural Intelligence and Technical/Trade Knowledge}

CQ enables a good understanding of culture and its meaning. This ability is probably built up gradually along with studying, especially when learning foreign language. In today's global era, people need to strengthen CQ training even more urgently. The disciplines of international relations, international politics, international business, and cross-culture psychology, offer rich theoretical and practical materials. The fields of cross cultural management and international human resources management combine practical experience and operational knowledge.

Within the discipline of foreign language, there should be appropriate increase of courses relating to culture, technology, and finance. For example, to the objectives of OBOR, the financial institutions including the Asian Investment Bank and the Silk Road Fund will need a large workforce with language capacity. The conventional foreign language study has emphasized on literature. As an adjustment, some foreign language disciplines should consider offer finance, economics, engineering as a minor, or even double degrees. In this way, the schools will be able to produce more cross-discipline and multi-skilled graduates, thus expand their employability.

Participating enterprises will of course devote substantial human and financial resources to prepare and create the workforce. These efforts call for guidance at macro-level. Take the China-Pakistan Economic Corridor as an example, the oil pipelines through Pakistan was planned initially, involving mainly petrochemical engineering and infrastructure enterprises. But with the revamping of the strategic planning, rail replaced oil pipeline as the mean of transportation. Consequently, the industries involved underwent a dramatic shift. The personnel preparation, including the plan of undergoing Urdu training in Pakistan also changed. In the meantime, Urdu training for workers building railroads and other infrastructures had to be added. Aside from linguistic talents, they also need to engage in the broader cultural training.

In addition to government programs and grants, business enterprises can also avail and retain talents by either providing scholarships or future employment opportunities, especially for those smaller language families with little use elsewhere and uncertain career prospects. Such an approach, which is akin to practices engaged by "Teacher's college" will benefit the companies by locking-in the talents they need. Furthermore, within such target-specific training programs, some pertinent business content can also be offered, such as technology, engineering, and finance, so that the students can become "custom-made talents." This improves their adaptability and creates a win-win situation for both business and foreign language talents.

\section{CONCLUSION}

One Belt and One Road initiative has brought the world into a new era of globalization and integration. Seizing the historical opportunities and building up human resource capacity, including language and cultural preparations, this paper proposed a model of Language and Cultural Pyramid (LCP). It constructs three layers: language intelligence, cultural intelligence, and philosophical intelligence. Not all three intelligences are required by every person involved in OBOR projects, but collectively, adequate capacities for the three layers need to be equipped by the work force to ensure the smooth implementation of OBOR initiatives. A successful OBOR will greatly promote peaceful co-existence and collective prosperity along the Belt and Road, and contribute to the whole world at large.

\section{REFERENCES}

[1] Report on OBOR, Yiou Intelligence, Dec. 2017

[2] Decoded: The Historical Development of the World Cultural Heritage 'Silk Road', Xinhua News Online, March 27, 2015.

[3] F. Richthofen, Einleitender Theil: Ergebnisse Eigener Reisen und Darauf gegrüNdeter Studien, 1877.

[4] Approaching the Ancient Maritime Silk Road, The People's Daily Online, February 21, 2015.

[5] Xi Jinping. Speech at the $19^{\text {th }}$ National Congress of CPC, Beijing, 2017.

[6] Xinhua News Online, December 4, 2015

[7] L. Zhao, "The cultural economics of One Belt, One Road," Annual Report on One Belt, One Road, The Commercial Press, p. 8, 2017.

[8] H. Wang and Y. Wang, "The linguistic situation of the countries along One Belt, One Road," The Linguistic and Strategic Research, vol. 2, no. 1, p. 14, 2016

[9] R. Ruiz, "Orientations in language planning," NABE Journal, vol. 8, no. 2, pp. $15-34,1984$

[10] A. Zhang, "Cultural intelligence and effective teaching," in Proc. the 11th International Symposium on Chinese Language, 2014.

[11] Y. Fang, Y. Fang, and J. Li, "How Singaporean enterprises appoint and manage their staff operating in China. International Business," vol. 10, p. 6, 1997.

[12] Marriott's Challenges Shared by Many International Corporations, Duowei news, Jan. 14, 2018 
[13] Y. Fang, Human Resource Management: Strategy and Implementation, McGraw Hill, 2008.

[14] Y. Fang and A. Zhang, "OBOR and human resources: Language and culture issues," Keynote speech at $2^{\text {nd }}$ National Summit of Language Strategy of China, Nanjing. Dec. 2015.

[15] Y. Fang, and A. Zhang, "One Belt and One Road initiatives and Human resource strategy: Pyramid of language-cultural capacity," China Language Strategy, vol. 4, no. 1, pp. 23-28, 2016.

[16] H. Gardner, Frames of Mind: The Theory of Multiple Intelligences, Basic Books, 1983.

[17] F. Fernandez-Martinez, Z. Kseniya, and M. Wolfgang. "Text categorization methods for automatic estimation of verbal intelligence," Expert Systems with Applications, vol. 39, no. 10, pp. 9807-9820, Aug. 2012.

[18] P. C. Earley and A. Soon. Cultural Intelligence: Individual Interactions across Cultures, Stanford, CA: Stanford University Press, 2003.

[19] A. Zhang, "Cultural intelligence and effective teaching: A case of Singapore," in Proc. 2nd National Summit of Language Strategy of China, Nanjing, Dec 2015.

[20] A. Zhang, "Cultural intelligence and effective teaching," in Proc. the 11th International Symposium on Chinese Language, 2014.

[21] OBOR and International Education Cooperation, Science China Press, Jan. 23, 2018.

[22] OBOR and International Education Cooperation, Science China Press, Jan. 23, 2018.

[23] Mandarin Gains Popularity among Russian Students, Channel Asia News, Oct 4, 2015

[24] Russia: All Set! Chinese in the Exam, Phonix News, March 15, 2018.

[25] Beijing University Officially Launches Public Courses on "One Belt, One Road" Foreign Language and Cultural Series, Sina News, September 16, 2015

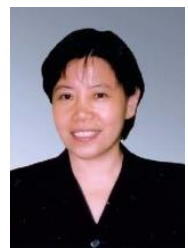

Aidong Zhang obtained her $\mathrm{PhD}$ in classical Chinese criticism (1996) from University of Toronto, Canada.

She has been teaching at the National Institute of Education's Asian Languages and Cultures Division since 1996. Dr Zhang teaches in the areas of modern Chinese literature, classical Chinese literature, and Chinese language and culture. Her current research covers classical Chinese literature, Chinese poetics, and comparative literature, as well as effective teaching.

Dr. Zhang has published in academic journals from USA, Canada, Australia, China, and Singapore, as well as Taiwan and Hong Kong. She authored and edited books by established publishers. She has served in the editorial board of international book series, and international academic journals. She has delivered keynote speeches to academic summit and international conferences. She has been invited to conduct workshops and seminars on topics of Chinese Literature, culture and literary theories for Chinese universities and for Singapore school clusters.

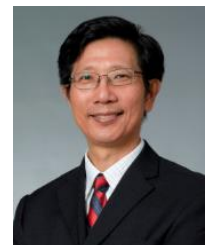

Yongqing Fang obtained his $\mathrm{PhD}$ in administration (1994) from Concordia University, Canada

Dr. Fang has taught in universities in Australia, Canada, China, and Singapore, as well as in Hong Kong, Taiwan, and Bhutan. He has published widely in international journals and his co-authored papers have won awards in Academy of Management (USA) and Administrative Science Association of Canada conferences. His books in management and human resource management have been published by McGraw-Hill and Thomson Learning.

He has acted as a consultant for organizations in Canada, China, and Southeast Asia, and served on management capacities in Canada and Singapore. He delivered a keynote speech to academic conferences and has been an invited speaker for academic and professional conferences and media. 